\title{
Fibromyalgia: the underdiagnosed disease of pain
}

\author{
Consuelo Rivera-Miranda Giral ${ }^{1}$ ID , Rosa Diaz-Manchay2 ${ }^{\text {ID }}$, Franco Leon-Jimenez ${ }^{3,4,5}$ ID \\ ${ }^{1}$ Medical School, Faculty of Medicine, Santo Toribio de Mogrovejo Catholic University, Chiclayo, Peru \\ ${ }^{2}$ Nursing School, Faculty of Medicine, Santo Toribio de Mogrovejo Catholic University, Chiclayo, Peru \\ ${ }^{3}$ Global Healthcare Center, Tumbes, Peru \\ ${ }^{4}$ Internal Medicine, Santa Rosa Hospital, Piura, Peru \\ ${ }^{5}$ Cayetano Heredia Peruvian University, Peru
}

\section{Dear Editor,}

The purpose of this letter is to explain the causes behind a late diagnosis in fibromyalgia. These are briefly presented below.

Fibromyalgia is a dynamic disease. Patients are classified under two phenotypes, one of them being more consistent with clinical criteria than the other. Also, fibromyalgia has two components: a central and peripheral one; but each can periodically dominate over the other [1]. For an unexperienced physician or one who just considers pain as the cardinal and only symptom, reaching a diagnosis might be difficult and the process slows down [2]. On the other hand, the health-disease morphophysiological paradigm, in which every pathology has to possess an evident structural correlation, is another factor that opposes fibromyalgia's variety of clinical manifestations.

Following this line, a 2017 Peruvian study applied to over 100 general practitioners working on primary care in Lambayeque stands out [2]. In this study none of them had acceptable knowledge regarding fibromyalgia, with outstanding ignorance of its diagnostic criteria [2].

It is important to note how discordance among clinicians has an influence at the moment of studying pain and its characteristics. This symptom might be present in other disorders with which fibromyalgia may coexist, thus leading to a late diagnosis. Moreover, there is reluctance among practitioners to take up these patients given the high psychological burden behind them; physicians are also subjected to their own beliefs and prejudices. The rejection negatively impacts the patients, who feel undermined by the people meant to improve their situation, acting as a motivator to keep consulting other healthcare professionals in order to find a solution [1, 3]

In addition, external consulting has limitations - so little time for so many patients. This drives physicians to shorten the time for anamnesis and physical exami- nation, leading to a wrong diagnosis [4]. This implies ineffective treatments along with pain's persistence, uncertain prognosis and poor satisfaction regarding medical care. The patient's desolation while dealing with crippling chronic pain affects every dimension of their lives, increased under the stress of being misunderstood by healthcare personnel and their environment.

Finally, it is important to recognize that with such an obstructive pathology as fibromyalgia, an early diagnosis should not be exclusively reserved for rheumatologists. It has to start with primary care in order to preserve life quality. In our context it has been diminished since hospitals are still focused on COVID-19 patients, leaving out every other patient; this represents a risk factor for diagnosis delay. Lockdowns also can trigger a fibromyalgia crisis through depression, anxiety, sleeping problems, lack of doctor's consultation and even exacerbations due to COVID-19 infection.

The authors declare no conflict of interest.

\section{References}

1. Kianmehr N, Haghighi A, Bidari A, et al. Are general practitioners well informed about fibromyalgia? Int I Rheum Dis 2015; 20: 13-26, DOI: 10.1111/1756-185X.12716.

2. Acuña F, Capitán V, León F. Conocimientos de fibromialgia en médicos de atención primaria de la provincia de Chiclayo-Perú, 2016. Reumatol Clin 2017; 13: 326-330, DOI: 10.1016/j.reuma. 2016.08.005

3. Ubago L, Ruiz P, Bermejo P, et al. Características clínicas y psicosociales de personas con Fibromialgia. Repercusión del diagnóstico sobres sus actividades. Rev Esp Salud Publica 2005; 79 : 683-695.

4. Galvez C, Duschek S, Del Paso G. Psychological impact of fibromyalgia: current perspectives. Psychol Res Behav Manag 2019; 12: 117-127, DOI: 10.2147/PRBM.S178240.

Address for correspondence:

Consuelo Rivera-Miranda Giral, Medical School, Faculty of Medicine, Santo Toribio de Mogrovejo Catholic University, Arturo Leandro Pastor 469, Lambayeque, Peru, e-mail: criveramisfit@gmail.com, ORCID: https://orcid.org/0000-0001-8399-9494 Submitted: 02.12.2020; Accepted: 18.01.2021 